06,03

\title{
Начальные стадии роста пленок титаната бария-стронция на подложке полуизолирующего карбида кремния
}

\author{
() А.В. Тумаркин ${ }^{1}$, И.Т. Серенков ${ }^{2}$, В.И. Сахаров ${ }^{2}$, С.В. Разумов ${ }^{1}$, А.А. Одинец ${ }^{1}$, \\ М.В. Злыгостов ${ }^{1}$, Е.Н. Сапего ${ }^{1}$, В.В. Афрросимов ${ }^{2}$ \\ ${ }^{1}$ Санкт-Петербургский государственный электротехнический университет „ЛЭТИ“, \\ Санкт-Петербург, Россия \\ ${ }^{2}$ Физико-технический институт им. А.Ф. Иофрфе, \\ Санкт-Петербург, Россия \\ E-mail: avtumarkin@yandex.ru \\ (Поступила в Редакцию 17 мая 2017 г. \\ В окончательной редакции 29 мая 2017 г.)
}

Впервые исследованы начальные стадии роста сегнетоэлектрических пленок титаната бария-стронция на подложках монокристаллического карбида кремния. Выбор подложки, обладающей высокой теплопроводностью, обусловлен возможностью применения данных структур в мощных сверхвысокочастотных устройствах. Определены диапазоны температур, разделяющие механизм поверхностной диффузии осаждаемых атомов от диффузии через газовую фазу при росте многокомпонентных пленок. Исследования показали, что массоперенос посредством поверхностной диффузии приводит к формированию зародышей малой высоты, покрывающих большую часть подложки, тогда как массоперенос атомов через газовую фазу приводит к образованию „столбчатой“ островковой структуры с малым процентом покрытия подложки и большей высотой островков.

А.В. Тумаркин и А.А. Одинец выражают благодарность за финансовую поддержку РФФИ (проект 16-29-05147 офи_м) и Минобрнауки России (государственное задание № 3.3990.2017.ПЧ).

DOI: 10.21883/FTT.2017.12.45230.157

\section{1. Введение}

Сегодня существует устойчивый интерес к сегнетоэлектрикам (СЭ), обусловленный сильной зависимостью диэлектрической проницаемости материала от приложенного электрического поля. Данное физическое явление позволяет реализовать такие сверхвысокочастотные (СВЧ) устройства, как вариконды с высокой добротностью, управляемые фильтры, линии задержки, фазовращатели [1-3]. Так, ключевой элемент фазированной антенной решетки - фазовращатель, сформированный на основе СЭ-пленки на диэлектрической подложке, потенциально обладает высоким быстродействием, малыми потерями в цепях управления, большой мощностью СВЧ-сигнала и низкой стоимостью массового производства [4]. Сочетание названных выше свойств в одном СВЧ-устройстве не удается осуществить на основе ферритовых или полупроводниковых материалов - ближайших конкурентов сегнетоэлектриков. В [4] показано, что максимально допустимая мощность СВЧсигнала на СЭ-фазовращателе может достигать $6 \mathrm{~W}$, тогда как полупроводниковые фазовращатели на полевом транзисторе или на основе варакторов на $p-n$-переходе не допускают работы с СВЧ-сигналом, мощность которого превосходит $0.01-0.02 \mathrm{~W}$.

Известно, что для сегнетоэлектрических элементов фактором, ограничивающим рабочую мощность устройства, является перегрев [5]. Одним из способов уменьшения перегрева рабочей области СВЧ-устройства пред- ставляется использование подложек с высоким коэффициентом теплопроводности. С этой точки зрения наиболее перспективной подложкой для мощных СВЧ-устройств является монокристаллический карбид кремния $(\mathrm{SiC})$, демонстрирующий на порядок больший коэффициент теплопроводности, чем широко используемый сапфир $\left(\mathrm{Al}_{2} \mathrm{O}_{3}\right)$. Реализация гетероструктуры „сегнетоэлектрическая пленка на карбиде кремния“ может привести к радикальному увеличению рабочих мощностей СВЧ-устройства. Основными достоинствами таких устройств будут являться простота технологии изготовления элементов, высокие уровни допустимой рабочей мощности и высокая радиационная стойкость. В работе [6] приводится исследование пленок $\mathrm{Ba}_{x} \mathrm{Sr}_{1-x} \mathrm{TiO}_{3}$ (BST) на подложках $\mathrm{SiC}$. Однако анализ экспериментальных данных диэлектрических потерь в емкостных структурах в диапазоне $1-100 \mathrm{kHz}$ не позволяет сделать вывод о применимости полученных пленок в СВЧ-диапазоне. Ранее авторами продемонстрирована принципиальная возможность получения тонкопленочной сегнетоэлектрической структуры $\mathrm{Ba}_{x} \mathrm{Sr}_{1-x} \mathrm{TiO}_{3}$ (BST) на подложке полуизолирующего карбида кремния методом ионно-плазменного распыления [7]. Тем не менее по нелинейности и добротности полученные пленки уступают структурам „ВST/ сапфир“ [8], что говорит о необходимости детальной разработки технологических подходов к осаждению многокомпонентных СЭ-пленок на карбид кремния. 
Источником важной информации, необходимой для понимания физики формирования сплошных пленок, является исследование начальных стадий их роста. Хорошо известно, что свойства тонких пленок (размеры кристаллитов, стехиометрия состава пленки и наличие включений вторичных фаз) в существенной мере зависят от тех условий, при которых осуществляются зарождение пленки на подложке и начальные этапы ее роста. Знание технологических условий, в которых преобладает конкретный механизм массопереноса адатомов, определяющий механизмы роста островков новой фазы, позволяет управлять структурой растущей пленки, а именно: элементным и фазовым составом и размерами кристаллитов [9-12].

Согласно теории [9], в технологических режимах, обычно реализуемых в методе ионно-плазменного распыления, т.е. когда транспорт вещества на подложку осуществляется через газовую фазу в условиях постоянной температуры и скорости формирования покрытия, управление структурой растущих пленок основано на возможности выбора температуры осаждения и интенсивности потока вещества, приходящего на подложку.

Начальный этап образования пленки - зародышеобразование - характеризуется появлением островков различных размеров и состава, причем этот рост может носить автоколебательный характер. Исследования методом рассеяния ионов средних энергий показали, что неоднородность островков по высоте и дальнейший переход к росту сплошного слоя зависят в значительной мере от согласования кристаллических решеток пленки и подложки [13].

Очевидно, что в зависимости от структуры и состава подложки время жизни адатомов на ее поверхности может меняться в широких пределах, что в свою очередь может приводить к смене механизмов их массопереноса. Так, на подложке с сильной связью между осаждаемыми частицами и подложкой будет реализован механизм поверхностной диффузии адатомов, а на подложке со слабой связью реализуется механизм диффузии в газовой фазе [9]. Это приведет к тому, что частицы в ансамбле, находящемся в условиях поступления на подложку постоянного во времени потока вещества, будут распределены по размерам совершенно различным образом.

В случае, если на подложке реализуется механизм поверхностной диффузии, постоянный во времени источник атомов приведет к тому, что островки будут иметь примерно одинаковые размеры, при этом их плотность останется постоянной во времени. Для случая, когда в системе реализуется механизм диффузии в газовой фазе, островки будут успевать поглощать все вещество с подложки таким образом, что пересыщение будет падать. При этом зародыши будут преимущественно расти в высоту [14], а плотность частиц будет убывать во времени $[9,10]$.

Известно, что температура осаждения является одним из основных факторов, определяющих механизм массопереноса в островковых пленках. При низких температу- рах, как правило, преобладает механизм поверхностной диффузии, а при высоких - механизм диффузии в газовой фазе [11].

Следовательно, на начальном этапе осаждения пленки в зависимости от температуры, материала подложки и мощности источника осаждаемых атомов можно осуществить два вида островкового роста. Один — „латеральный“ рост достаточно гладких островков высотой от одной постоянной решетки, занимающих большую площадь, реализуемый при поверхностной диффузии компонентов. Второй — „вертикальный“ рост пирамидальных островков при минимальном покрытии подложки, возможный при массопереносе посредством газовой фазы.

Ранее авторами определены диапазоны технологических параметров, в которых реализуются те или иные механизмы роста СЭ-пленок BST на сапфире [14-16], но в современной научной литературе не найдено упоминаний об исследовании начальных стадий роста сегнетоэлектрических пленок на $\mathrm{SiC}$. В связи с этим целью данной работы является выявление механизмов зарождения слоев титаната бария-стронция на подложке карбида кремния для разработки основ управляемого синтеза сегнетоэлектрических пленок с заданными свойствами для СВЧ-электроники.

\section{2. Эксперимент}

Подложки полуизолирующего карбида кремния политипа $6 \mathrm{H}(\mathrm{SiC}-6 \mathrm{H})$ (c-срез) качества „ерi-ready“ диаметром $3^{\prime \prime}(76.2 \mathrm{~mm})$ изготавливались из монокристаллических слитков, выращенных методом газофазного транспорта и осаждения на установках, реализованных на площадке ЗАО „Светлана-Электронприбор“.

Пленки BST осаждались методом ионно-плазменного распыления керамической мишени состава $\mathrm{Ba}_{0.4} \mathrm{Sr}_{0.6} \mathrm{TiO}_{3}$ в течение 30-60 s, что соответствует островковой стадии формирования покрытия [14]. Перед процессом осаждения проводилось предраспыление мишени в стороне от подложкодержателя в течение $30 \mathrm{~min}$ с целью очистки поверхности. В процессе осаждения использовались следующие параметры газового разряда: напряжение разряда $U=1 \mathrm{kV}$, ток разряда $I=140 \mathrm{~mA}$, давление рабочего газа $P=10 \mathrm{~Pa}$. В качестве рабочего газа использовался чистый кислород с целью формирования бездефектной перовскитной структуры пленок. Температура подложек $T_{s}$ контролировалась при помощи термопары, расположенной под подложкодержателем, и менялась в диапазоне $700-880^{\circ} \mathrm{C}$. После осаждения образцы охлаждались в кислороде при атмосферном давлении со скоростью порядка $2-3^{\circ} \mathrm{C} / \mathrm{min}$. Выбор состава распыляемой мишени и технологических параметров осаждения сделан на основе результатов предыдущих исследований, позволивших определить область технологических параметров для получения пленок BST с электрофизическими характеристиками, достаточными для СВЧ применений [17]. 
Характеристики исследованных $\mathrm{Ba}_{x} \mathrm{Sr}_{1-x} \mathrm{TiO}_{3}$ пленок

\begin{tabular}{|c|c|c|c|c|c|c|c|c|c|c|c|}
\hline \multirow{2}{*}{ № } & \multirow{2}{*}{ Подложка } & \multirow{2}{*}{$\begin{array}{l}T_{s}, \\
{ }^{\circ} \mathrm{C}\end{array}$} & \multirow{2}{*}{$\begin{array}{c}\tau, \\
\mathrm{s}\end{array}$} & \multirow{2}{*}{ M.a. } & \multirow{2}{*}{$\begin{array}{c}C, \\
\%^{* *}\end{array}$} & \multicolumn{2}{|c|}{$h_{c o v}$} & \multicolumn{3}{|c|}{$\Delta h_{\text {cov }}$} & \multirow{2}{*}{$\begin{array}{c}x \\
\text { в BST }\end{array}$} \\
\hline & & & & & & $a$ & $b$ & $a$ & $b$ & $c$ & \\
\hline 2253 & $\mathrm{SiC}$ & 880 & 60 & 8.1 & 9 & 94 & 12.7 & 26 & 3.5 & 0.28 & 0.36 \\
\hline 2254 & $\mathrm{SiC}$ & 880 & 30 & 5.3 & 7 & 76 & 10.3 & 20 & 2.7 & 0.26 & 0.32 \\
\hline 2255 & $\mathrm{SiC}$ & 800 & 60 & 7.5 & 29 & 26 & 3.5 & 17 & 2.3 & 0.65 & 0.36 \\
\hline 2256 & $\mathrm{SiC}$ & 800 & 30 & 4.5 & 16 & 28 & 3.8 & 18 & 2.4 & 0.64 & 0.36 \\
\hline 2257 & $\mathrm{SiC}$ & 700 & 60 & 8.0 & 31 & 26 & 3.5 & 17 & 2.3 & 0.65 & 0.36 \\
\hline 2258 & $\mathrm{SiC}$ & 700 & 30 & 4.0 & 17 & 23 & 3.1 & 15 & 2.0 & 0.65 & 0.36 \\
\hline 2196 & $\mathrm{Al}_{2} \mathrm{O}_{3}$ & 880 & 40 & 5.6 & 14 & 40.3 & 4.96 & 15.6 & 1.92 & 0.39 & 0.38 \\
\hline 2193 & $\mathrm{Al}_{2} \mathrm{O}_{3}$ & 800 & 40 & 4.9 & 52 & 9.5 & 1.17 & 7.0 & 0.86 & 0.74 & 0.36 \\
\hline 2189 & $\mathrm{Al}_{2} \mathrm{O}_{3}$ & 600 & 40 & 6.2 & 52 & 11.9 & 1.46 & 8.8 & 1.1 & 0.74 & 0.30 \\
\hline
\end{tabular}

Примечание. M.a. (matter amount) - измеренное количество вещества в пленке в единицах $10^{15}$ объединенных атомов (далее - аtoms) на $\mathrm{cm}^{2}$, где „объединенный атом“ - молекула $\left(\mathrm{Ba}_{x} \mathrm{Sr}_{1-x}\right)_{0.2} \mathrm{Ti}_{0.2} \mathrm{O}_{0.6} ; C$ (coverage rate) - измеренная степень покрытия пленкой подложки; $h_{c o v}$ (on covered areas) - толщина пленки на покрытых участках поверхности подложки; $a-$ в единицах $10^{15}$ atoms $/ \mathrm{cm}^{2}, b-$ в $\mathrm{nm}($ в предположении плотности $\left.5.0 \mathrm{~g} / \mathrm{cm}^{3}\right) ; \Delta h_{\text {cov }}$ - разброс толщин на покрытых участках; $a, b$ - как и в предыдущих столбцах, $c$ - относительный разброс $\left(\Delta h_{\text {cov }} / h_{\text {cov }}\right)$. Подробно о вычислениях разброса толщин см. [18].

Структура островковых пленок исследовалась методом рассеяния ионов средних энергий (РИСЭ), являющимся модификацией широко применяемого метода Резерфордовского обратного рассеяния ионов (РОР) и отличающимся от последнего диапазоном энергий ионов зондирующего пучка (единицы-десятки $\mathrm{MeV}$ в POP и десятки-сотни $\mathrm{keV}$ в РИСЭ). Снижение энергии ионного пучка позволяет, за счет применения электростатических анализаторов энергий обратнорассеянных ионов, получить высокое, до $0.5 \mathrm{~nm}$, разрешение по глубине, что особенно важно при исследовании начальных стадий роста пленок [18].

В данной работе для исследования пленок применялись пучки ионов $\mathrm{He}^{+}$и $\mathrm{H}^{+}$, для регистрации которых использовались электростатический анализатор и полупроводниковый спектрометрический детектор соответственно. Угол рассеяния составлял $120^{\circ}$. Для каждого образца были получены энергетические спектры рассеянных ионов в режиме произвольной ориентации пучка ионов $Y_{r}(E)$ и в режиме каналирования $Y_{c}(E)$. На основании зависимости $Y_{r}(E)$ путем сопоставления экспериментально измеренных и расчетных спектров определялся состав пленок, их толщина, а также разброс в толщине и степень покрытия подложки пленкой.

\section{3. Результаты и обсуждение}

В ходе работы методом РИСЭ исследовались образцы, переменным технологическим фактором для которых являлась температура подложки при неизменном давлении $(10 \mathrm{~Pa})$. Другие технологические параметры (плотность потока осаждаемых компонентов, мощность разряда, скорость нагрева и охлаждения образцов) поддерживались постоянными. Технологические параметры режимов осаждения и результаты исследования пленок методом РИСЭ сведены в таблицу. В ней указаны температура подложки $T_{s}$, время осаждения образцов $\tau$, измеренное количество вещества M.a. в образцах, степень покрытия пленкой подложки $C$, средняя толщина пленки $h_{c o v}$ на покрытых участках поверхности подложки (высота островков), разброс пленок по толщине $\Delta h_{c o v}$ и компонентный состав исследуемых пленок (содержание $\mathrm{Ba}$ ). Данные по образцам BST на сапфире [16] включены в таблицу для сопоставления механизмов роста исследуемых пленок на данных подложках.

Bce приведенные в таблице величины получены в результате моделирования РИСЭ-спектров, где они являются варьируемыми параметрами итерационной процедуры. Подробно о технике моделирования см. [18], здесь же отметим, что высота пиков $\mathrm{Ba}, \mathrm{Sr}$ и Ті относительно уровня сигнала кремния подложки определяется степенью покрытия, энергетическая ширина пиков средней толщиной на покрытых участках, отношение амплитуд - элементным составом, протяженность задних (низкоэнергетичных) фронтов - разбросом высот островков. Пример моделирования РИСЭ-спектра показан на врезке рис. 2.

Сопоставление спектров обратно рассеянных ионов $Y_{c}(E)$ и $Y_{r}(E)$, используемое для определения наличия монокристаллической фракции в исследуемых слоях, не выявило каналирования легких ионов в пленках $\mathrm{Ba}_{x} \mathrm{Sr}_{1-x} \mathrm{TiO}_{3}$ на подложках карбида кремния. Данный факт свидетельствует об отсутствии монокристаллической упорядоченности в образцах. Подложка $\mathrm{SiC}$ политипа $6 H \quad c$-среза обладает гексагональной структурой с постоянной решетки $0.3081 \mathrm{~nm}$, тогда как параметр кубической решетки для твердого раствора состава $\mathrm{Ba}_{0.4} \mathrm{Sr}_{0.6} \mathrm{TiO}_{3}$ составляет $0.3946 \mathrm{~nm}$. Значительная разница в параметрах решетки (28\%) способствует возникновению сильных механических напряжений в формируемых образцах на начальных стадиях роста, подобно ситуации роста BST-пленок на сапфире. Как известно [15], на начальной стадии осаждения BST-пленок на поверхности сапфира образуется напряженный слой, 
который наследует структуру подложки. Данный слой трансформируется в зародыши новой фазы в результате релаксации упругой энергии за времена порядка $40 \mathrm{~s}$ при $T_{s}=800^{\circ} \mathrm{C}$. Поскольку подложка карбида кремния оказывает гораздо более сильное воздействие на растущую BST-пленку чем сапфир, можно предположить, что в данном случае релаксация упругой энергии должна происходить за меньшее время. Данное обстоятельство должно сказаться на механизмах зародышеобразования BST-пленок на карбиде кремния.

На рис. 1 и 2 изображены спектры обратнорассеянных ионов $\mathrm{He}^{+}$от островковых BST-пленок, осажденных при различных температурах подложки на карбид кремния в течение 30 и $60 \mathrm{~s}$ соответственно. В исследуемом диапазоне температур пики, соответствующие отдельным

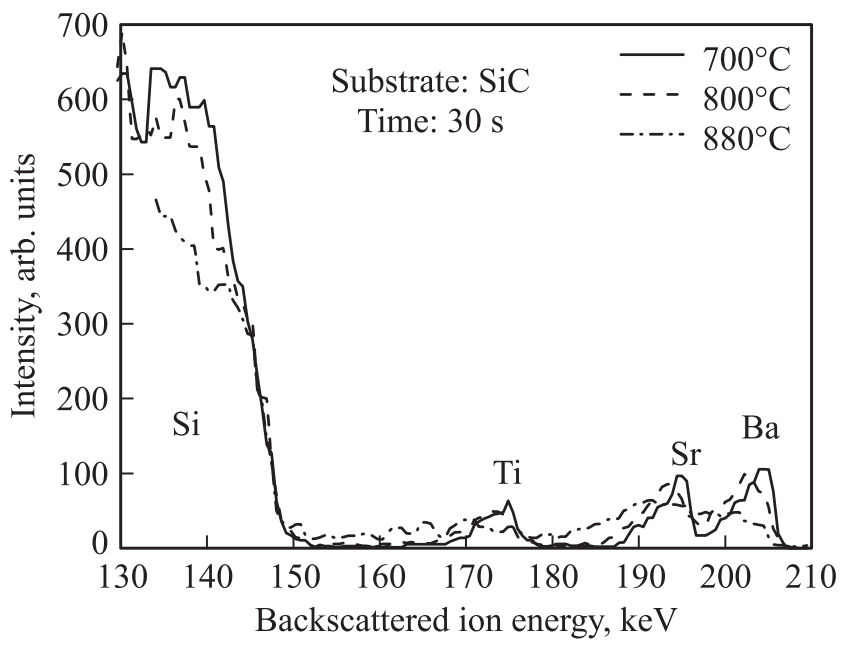

Рис. 1. Спектры обратнорассеянных ионов от пленок BST, осажденных на карбид кремния при различных температурах в течение $30 \mathrm{~s}$. Зондирующий пучок $-\mathrm{He}^{+}$с исходной энергией $227 \mathrm{keV}$.

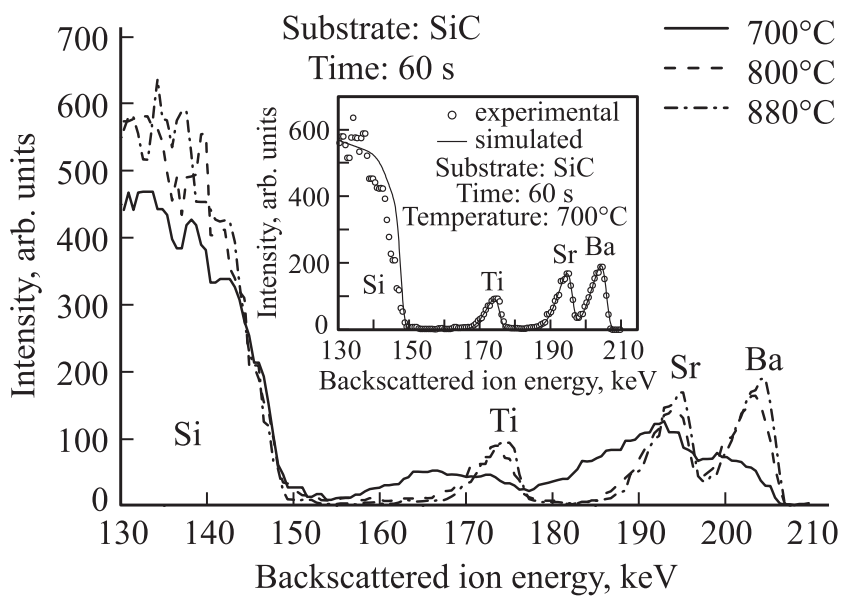

Рис. 2. Спектры обратнорассеянных ионов от пленок BST, осажденных на карбид кремния при различных температурах в течение $60 \mathrm{~s}$. Зондирующий пучок $-\mathrm{He}^{+}$с исходной энергией $227 \mathrm{keV}$. Врезка - результат моделирования РИСЭ-спектра образца 2257 (см. таблицу).

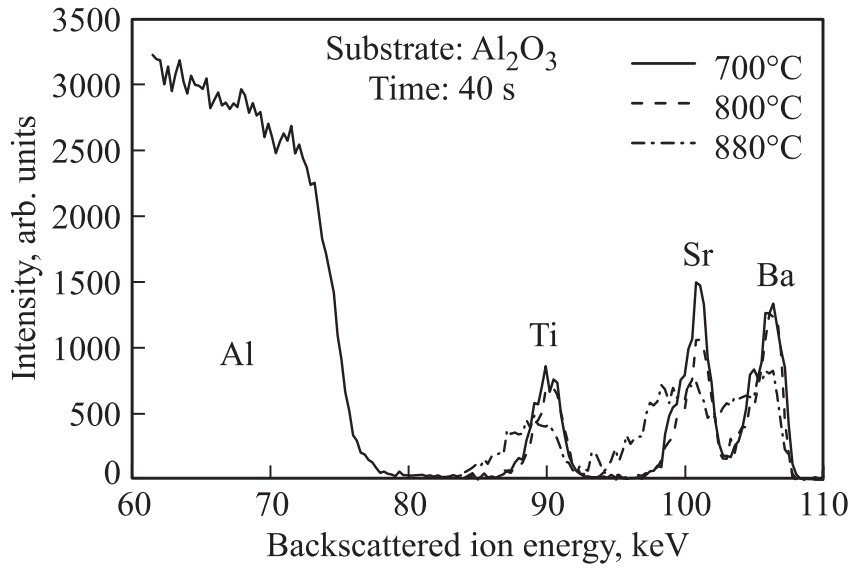

Рис. 3. РИСЭ-спектры образцов, осажденных на сапфир при различных температурах в течение $40 \mathrm{~s}$. Зондирующий пучок $-\mathrm{He}^{+}$с исходной энергией $116 \mathrm{keV}$.

элементам, имеют сходную треугольную форму с сильно затянутым низкоэнергетичным фронтом, что свидетельствует о пирамидальной форме островков (разброс толщин $\Delta h_{\text {cov }}$ значительно превосходит постоянную решетки BST). Для сравнения на рис. 3 приведены спектры обратнорассеянных ионов от островковых пленок BST на сапфире, осажденных в подобных технологических условиях. При сопоставлении спектров обращают на себя внимание три факта: а) для всех исследованных пленок при переходе к $T_{s}=880^{\circ} \mathrm{C}$ форма пиков кардинально меняется, что свидетельствует о возникновении тенденции вертикального роста островков; б) сходное изменение формы пиков при увеличении температуры осаждения на обеих подложках говорит о похожих механизмах массопереноса в данном температурном диапазоне; в) существенно большая протяженность низкоэнергетичных фронтов в случае подложки карбида кремния свидетельствует о различной геометрии островков на $\mathrm{SiC}$ и $\mathrm{Al}_{2} \mathrm{O}_{3}$.

Проанализируем эволюцию BST-островков на карбиде кремния во времени. На рис. 4 и 5 приведены зависимости степени покрытия пленкой подложки и средней высоты островков от температуры осаждения для пленок, осаждавшихся на $\mathrm{SiC} 30$ и $60 \mathrm{~s}$ соответственно. В диапазоне $T_{s}=700-800^{\circ} \mathrm{C}$ доля площади подложки, покрытой островками, приблизительно пропорциональна времени осаждения, тогда как высота островков, осаждавшихся 30 и $60 \mathrm{~s}$, практически одинакова. Это говорит о том, что при низких температурах островки, достигая высоты в 8-10 элементарных ячеек, в дальнейшем растут латерально. При увеличении $T_{s}$ до $880^{\circ} \mathrm{C}$ высота островков резко возрастает. Степень покрытия в этом случае минимальна, а все растущие островки имеют близкие высоты и малые относительные разбросы толщин, так что они представляют собой объекты цилиндрической формы. Данную тенденцию можно объяснить тем, что при увеличении температуры осаждения 


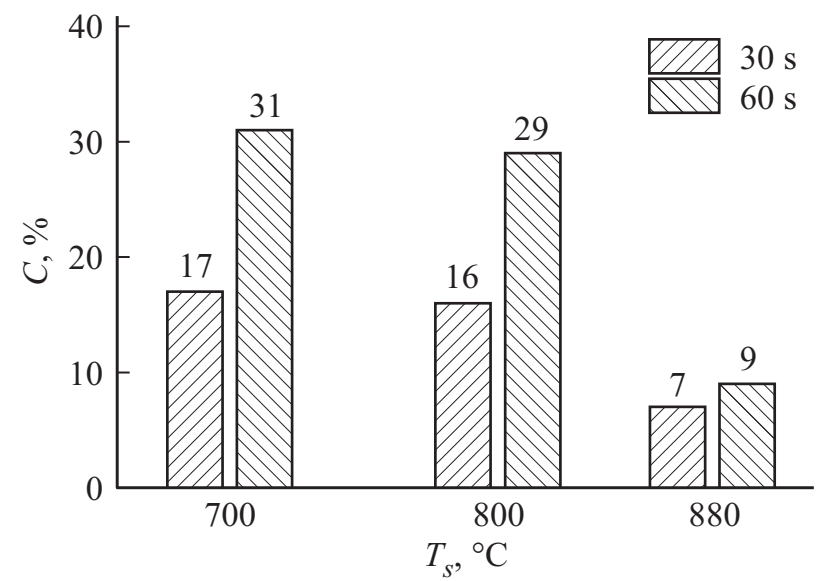

Рис. 4. Зависимость степени покрытия подложки карбида кремния BST островками от температуры осаждения.

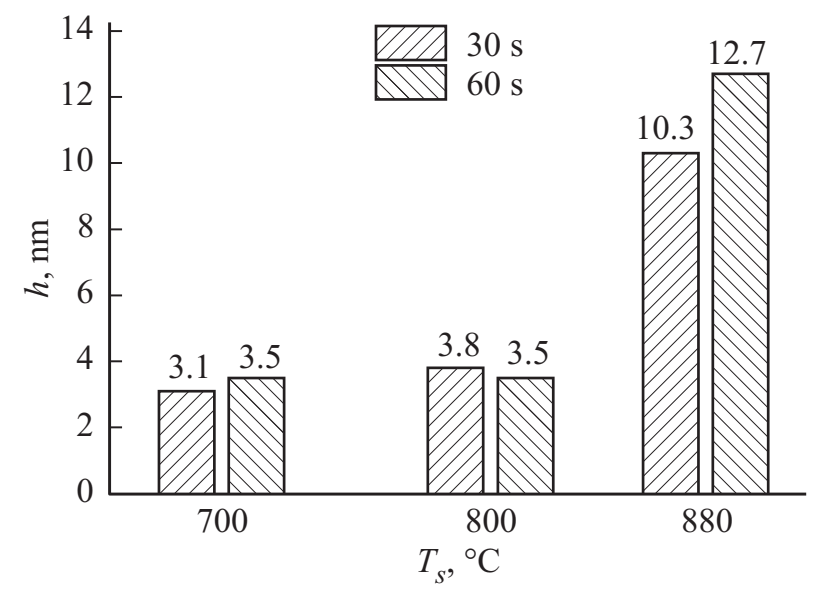

Рис. 5. Зависимость высоты BST островков на карбиде кремния от температуры осаждения.

происходит смена механизма массопереноса адатомов с поверхностной диффузии на диффузию через газовую фазу, когда диффундирующие в приповерхностном газовом слое атомы присоединяются преимущественно к верхней поверхности островков.

На рис. 6 и 7 приведены зависимости степени покрытия пленкой подложки и средней высоты островков от температуры осаждения пленок BST на карбиде кремния в сравнении с островковыми пленками BST на сапфире. Из зависимостей видно, что увеличение $T_{s}$ от 700 до $880^{\circ} \mathrm{C}$ приводит к уменьшению площади подложки $\mathrm{SiC}$, занятой островками, от 17 до 7\% (рис. 6) при одновременном увеличении высоты островков от 3.1 до $10.3 \mathrm{~nm}$ (рис. 7). Тенденция аналогична начальным стадиям роста BST-пленок на сапфире. В обоих случаях имеет место резкое сокращение площади подложки, занимаемой островками, и увеличение их высоты при переходе $T_{s}$ от 800 к $880^{\circ} \mathrm{C}$, свидетельствующее об изменении механизма массопереноса. Разница между подложками заключается в том, что на карбиде кремния островки занимают существенно меньшую площадь при значительно больших высотах во всем исследуемом диапазоне температур осаждения, что может быть объяснено существенно меньшим временем релаксации упругой энергии начального BST-слоя на данной подложке.

Необходимо отметить, что при нагреве подложки карбида кремния в кислородной атмосфере вероятен процесс ее окисления с образованием на поверхности диоксида кремния $\mathrm{SiO}_{2}$. Результаты исследований процесса окисления $\mathrm{SiC}$ в кислороде при температуpax выше $1000^{\circ} \mathrm{C}$ представлены во многих работах (см., например, обзоры $[19,20])$. Большинство авторов рассматривает окисление $\mathrm{SiC}$, как необходимый процесс в той или иной технологической цепочке, что и обосновывает выбор температур оксидирования. Вместе с тем процесс окисления карбида кремния при температурах менее $1000^{\circ} \mathrm{C}$ практически не изучен из-за малой скорости образования оксида.

В нашем случае при исследовании образцов методом РИСЭ наличие окисла подтверждается возникновением характерного пика кислорода в спектре обратнорассеянных протонов. На рис. 8 приведены спектры рассеяния

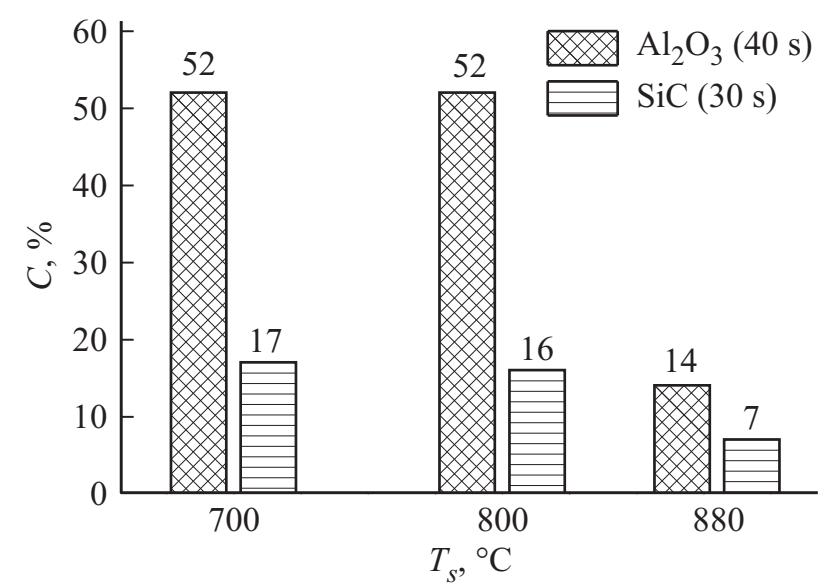

Рис. 6. Зависимость степени покрытия подложки пленкой на сапфире и карбиде кремния от температуры осаждения.

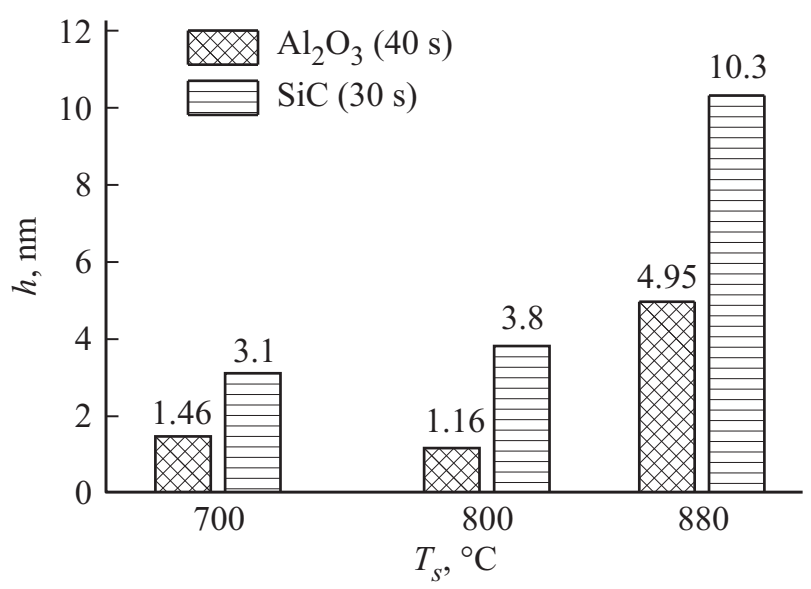

Рис. 7. Зависимость высоты островков на сапфире и карбиде кремния от температуры осаждения. 


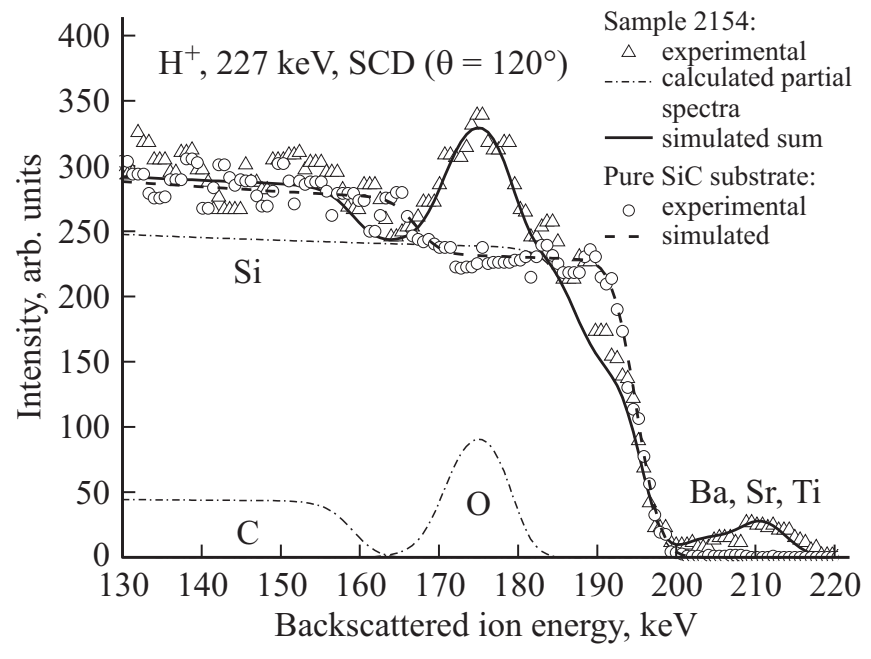

Рис. 8. Спектры обратнорассеянных ионов от островковой пленки BST на карбиде кремния и от чистой подложки SiC.

протонов от одного из образцов BST / $\mathrm{SiC}$ в сравнении со спектром от чистой подложки, не подверженной нагреву в кислороде. Исходя из протяженности пика кислорода, толщина слоя диоксида кремния на поверхности $\mathrm{SiC}$ составляет порядка $15 \mathrm{~nm}$.

В случае роста СЭ-пленок на карбиде кремния процесс его окисления можно рассматривать как нежелательный из-за возможного ухудшения теплоотвода. С другой стороны, принципиальная возможность формирования перовскита BST на подложках диоксида кремния продемонстрирована, например, в [21]. В любом случае для изучения влияния слоя $\mathrm{SiO}_{2}$ на поверхности $\mathrm{SiC}$ на дальнейший рост $\mathrm{C} Э$ пленок, как и для ответа на вопросы о сплошности слоя оксида, его кристаллической структуре и скорости образования, необходимо проведение отдельных исследований.

\section{4. Заключение}

Температура подложки определяет механизмы зарождения и формирования пленок $\mathrm{BaSrTiO}_{3}$ на карбиде кремния. Изменение температуры подложки позволяет управлять механизмами массопереноса распыленных атомов до их встраивания в растущую пленку. При низких температурах осаждения наблюдается доминирование механизма массопереноса за счет диффузии атомов по поверхности подложки, вследствие чего формируются зародыши малой высоты, покрывающие большую часть подложки.

Повышение температуры на начальном этапе конденсации приводит к образованию „столбчатой“ островковой структуры с малым процентом покрытия подложки и большей высотой островков, что свидетельствует о механизме массопереноса атомов через газовую фазу.

Наличие столбчатой структуры на начальной стадии роста сегнетоэлектрических слоев позволяет предполо- жить, что при дальнейшем росте пленки может сформироваться преимущественно ориентированная фаза. Осаждение из паровой фазы, при повышенной температуре подложки, позволяет получить слабые источники вещества и реализовать предельно малые скорости конденсации. Таким образом, стимулируются процессы ориентированной кристаллизации на поверхности подложки, что может приводить к образованию преимущественно ориентированных пленок.

\section{Список литературы}

[1] C. Luo, J. Ji, F. Ling, D. Li, J Yao. J. Alloys Comp. 687, 458-462 (2016).

[2] J.W. Kim, H. Shima, T. Yamamoto, S. Yasui, H. Funakubo, T. Yamada, K. Nishida. Proc. IEEE ISAF, 7172665 (2016).

[3] Г.Я. Красников, Н.А. Зайцев, В.П. Бокарев, Ю.И. Плотников. Электронная техника. Сер. 3. Микроэлектроника 1, 161, 42 (2016).

[4] О.Г. Вендик. ФТТ 51, 1441 (2009).

[5] O. Soldatenko, T. Samoilov, A. Ivanov, A. Kozyrev, D. Ginley, T. Kaydanova. Appl. Phys. Lett. 89, 232 (2006).

[6] L. Song, Y. Chen, G. Wang, L. Yang, J. Ge, X. Dong, P. Xiang, Y. Zhang, X. Tang. J. Am. Ceram. Soc. 97, 3048 (2014)

[7] А.В. Тумаркин, С.В. Разумов, А.Г. Гагарин, А.А. Одинец, А.К. Михайлов, И.П. Пронин, В.М. Стожаров, С.В. Сенкевич, Н.К. Травин. ПЖТФ 42, 8, 70 (2016).

[8] S.V. Razumov, A.V. Tumarkin, M.M. Gaidukov, A.G. Gagarin, A.B. Kozyrev, O.G. Vendik, A.V. Ivanov, O.U. Buslov, V.N. Keys, L.C. Sengupta, X. Zhang. Appl. Phys. Lett. 81, 1675 (2002).

[9] С.А. Кукушкин, В.В. Слезов. Дисперсные системы на поверхности твердых тел. Механизмы образования тонких пленок (эволюционный подход). Наука, СПб. (1996). $304 \mathrm{c}$.

[10] S.A. Kukushkin, A.V. Osipov. J. Appl. Phys. 86, 1370 (1999).

[11] S.A. Kukushkin. Thin Solid Films 207, 302 (1992).

[12] S.A. Kukushkin, A.V. Osipov. Prog. Surf. Sci. 51, 1 (1996).

[13] В.В. Афросимов, Р.Н. Ильин, С.Ф. Карманенко, В.И. Сахаров, И.Т. Серенков. ФТТ 45, 1070 (2003).

[14] А.В. Тумаркин, И.Т. Серенков, В.И. Сахаров. ФТТ 52, 2397 (2010).

[15] А.В. Тумаркин, С.А. Кукушкин, А.В. Осипов, А.В. Анкудинов, А.А. Одинец. ФТТ 57, 796 (2015).

[16] А.В. Тумаркин, И.Т. Серенков, В.И. Сахаров, В.В. Афросимов, А.А. Одинец. ФТТ 58, 354 (2016).

[17] А.В. Тумаркин, В.И. Альмяшев, С.В. Разумов, М.М. Гайдуков, А.Г. Гагарин, А.Г. Алтынников, А.Б. Козырев. ФТТ 57, 540 (2015).

[18] V.V. Afrosimov, R.N. Il'in, S.F. Karmanenko, F.F. Melkov, V.I. Sakharov, I.T. Serenkov. Thin Solid Films 492, 146 (2005).

[19] J. Roy, S. Chandra, S. Das, S. Maitra. Rev. Adv. Matter Sci. 38, 29 (2014).

[20] R.G. Munro, S.J. Dapkunas. J. Res. Natl. Inst. Stand. Technol. 98, 607 (1993).

[21] С.В. Разумов, А.В. Тумаркин, М.В. Сыса, А.Г. Гагарин. ПЖТФ 29, 1 (2003) 